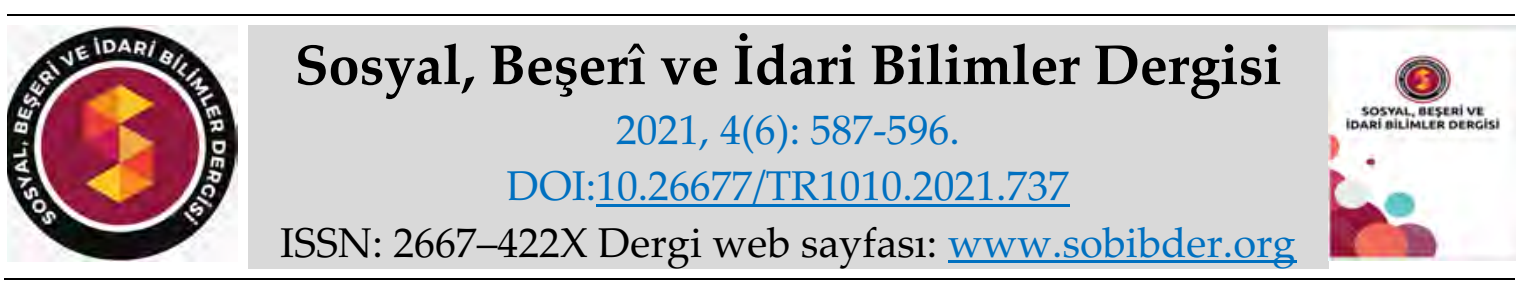

KAVRAMSAL MAKALE

\title{
Fonksiyonel Bir Gıda: Zeytinyağı
}

Arş. Gör. Duygu KIRMIZIKUŞAK, Karabük Üniversitesi, Safranbolu Turizm Fakültesi, Karabük, e-posta: duygukirmizikusak@karabuk.edu.tr

ORCID: https://orcid.org/0000-0002-7686-1160

Dr. Öğr. Üyesi Melek YAMAN, Ankara Hacı Bayram Veli Üniversitesi, Turizm Fakültesi, Ankara, e-posta: melek.yaman@hbv.edu.tr

ORCID: https://orcid.org/0000-0002-6281-0880

Öz

Son dönemde kişiler, obezite ve buna bağlı olarak gelişen sağlık sorunlarının artmasından dolayı diyetlerinde yer alan yararlı ve zararlı bileşenlerin önemi konusunda bilinçlenmiştir. Kişilerin sağlıklı olan gıdalara yönelimi tarihten beri çok kullanılan sağlık deposu gıdaların değerini ve önemini tekrar gözler önüne sermiştir. Özellikle, büyük oranda zeytinyağına bağlı olan Akdeniz diyeti ile beslenen kişilerin koroner kalp hastalığı, prostat, kolon kanserlerine daha az yakalandığına dair çalışmalar dikkatleri zeytinyağına çekmiştir. Bu çalışma nitel yöntemle gerçekleştirilmiş bir derleme çalışmasıdır. Çalışmada, zeytinyağının, kişilerin genel sağlık durumuna katkıda bulunabilecek fonksiyonel bir gıda örneği olduğuna vurgu yapılmış, Türk mutfak kültüründe zeytinyağı kullanımı değerlendirilmiştir.

Anahtar Kelimeler: Zeytinyağı, Zeytin, Sağlık, Akdeniz Diyeti, Türk Mutfak Kültürü.

Makale Gönderme Tarihi: 23.03.2021

Makale Kabul Tarihi: 02.06.2021

\section{Önerilen Atıf:}

Kızmızıkuşak, D. ve Yaman, M (2021). Fonksiyonel Bir Gıda: Zeytinyağı, Sosyal, Beşeri ve İdari Bilimler Dergisi, 4(6): 587-596.

(c) 2021 Sosyal, Beşerî ve İdari Bilimler Dergisi. 


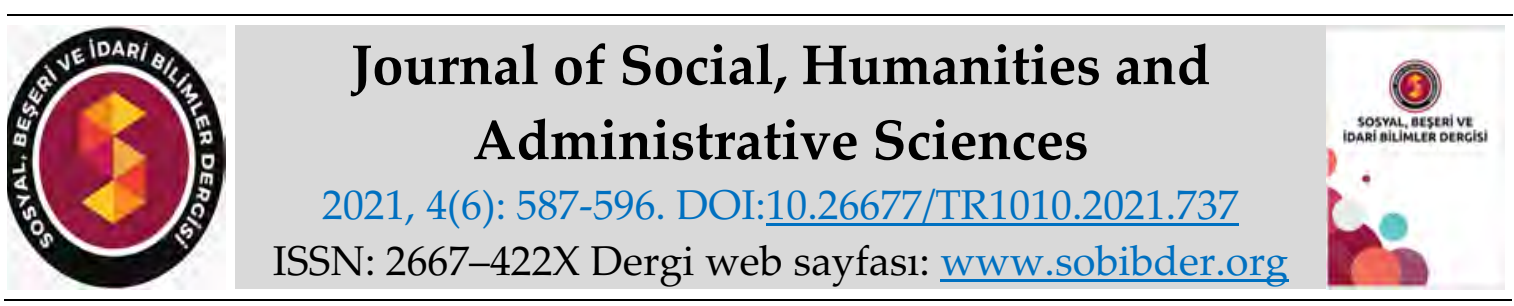

\title{
CONCEPTUAL PAPER
}

\section{A Functional Food: Olive Oil}

Research Assistant Duygu KIRMIZIKUŞAK, Karabük University, Safranbolu Faculty of Tourism, Karabük, e-mail: duygukirmizikusak@karabuk.edu.tr

ORCID: https://orcid.org/0000-0002-7686-1160

Assistant Prof. Dr. Melek YAMAN, Ankara Hacı Bayram Veli University, Faculty of Tourism, Ankara, e-mail: melek.yaman@hbv.edu.tr

ORCID: https://orcid.org/0000-0002-6281-0880

\begin{abstract}
Recently, people have become aware of the importance of beneficial and harmful components in their diets due to the increase in obesity and related health problems. People's orientation towards healthy foods has once again revealed the value and importance of health store foods, which have been widely used since history. Especially, studies showing that people who are feed with the Mediterranean diet, which is largely dependent on olive oil, have less coronary heart disease, prostate and colon cancers have drawn attention to olive oil. This study is a qualitative compilation study. In the study, it was emphasized that olive oil is a functional food that can contribute to the general health status of the people, and the use of olive oil in Turkish cuisine culture was evaluated
\end{abstract}

Keywords: Olive Oil, Olive, Health, Mediterranean Diet, Turkish Cuisine Culture

Received: 23.03 .2021

Accepted: 02.06.2021

\section{Suggested Citation:}

Kızmızıkuşak, D. ve Yaman, M. (2021). A Functional Food: Olive Oil, Journal of Social, Humanities and Administrative Sciences, 4(6): 587-596.

(c) 2021 Sosyal, Beşerî ve İdari Bilimler Dergisi. 


\section{Gíriş}

Bireyler, obezite ile ilgili sorunlarının artmasından dolayı genel sağlık durumlarının korunması için diyet bileşenlerinin önemi konusunda çok daha bilinçlidir. Bu bileşenlerin içinde, özellikle Batılı ülkelerde yağlar oldukça belirgin bir şekilde öne çıkmıştır. Beslenme uzmanlarının önerdikleri diyet planı genellikle tüketilen doymuş yağ miktarını azaltma ve çoklu doymamış yağ oranını arttırma şeklindedir (Harwood ve Yaqoob, 2002: 685).

Zeytin ağacı, uzun ömürlülüğü ile bilinen, dar gümüşi yaprakları ve küçük beyaz çiçekleri olan nispeten küçük, yaprak dökmeyen bir ağaçtır. Zeytinin botanik atasının, hala Akdeniz çevresinde yetişen, küçük, ssska bir meyveye sahip yabani bir zeytin türü olan oleaster, olea sylvestris olduğu düşünülmektedir (Harwood ve Yaqoob, 2002: 685).

Zeytinyağı, zeytin ağacının meyvesinden elde edilen yağdır. Optimum olgunluk zamanı, yıllar, ekim alanları, aynı korudaki ağaçlar veya aynı ağaçtaki ayrı meyveler arasında değişiklik göstermektedir. Sağlam zeytin meyvesinden mekanik yollarla elde edilen yağ, sızma zeytinyağ1 olarak bilinmekte ve ek işlem yapılmadan pazarlanmaktadır (Kiritsakis ve Markakis, 1988; Aparicio ve Harwood, 2013).

Zeytinyağ 1 \% 72-75 oleik asit, \% 13-16 elaidic asit, \%11-14 doymuş yağ asidi (SFA) palmitik asit, $\%$ 2-3 stearik asit ve \% 6-11,5 PUFA, \% 5-11 linoleik asit ve \% 0,3-0,5 linolenik asitten oluşmaktadır (Gerber, 1997: 91-92).

Zeytin yetiştiriciliği geleneksel olarak Akdeniz bölgesinde yoğunlaşmaktadır. Güney Avrupa ülkeleri dünya zeytinyağı üretiminin yaklaşık \%74,9'unu oluşturmaktadır (Baldoni ve Belaj, 2009). Dünya zeytinyağı arzının çoğu Akdeniz ülkelerinden gelmektedir (Kiritsakis ve Shahidi, 2017). Kaliteli zeytinyağ tarafından sevilen kokulu ve hassas bir tada sahiptir (Kiritsakis, Turkan ve Kiritsakis, 2005: 35).

Zeytinyağının tüketimi, kansere (Waterman ve Lockwood, 2007) ve koroner kalp hastalığına (Kiritsakis ve Shahidi, 2017) karşı önemli ölçüde koruma sağlarken oksidatif stresi inhibe ederek yaşlanmayı geciktirmektedir (Kiritsakis, Turkan ve Kiritsakis, 2005; Kiritsakis ve Shahidi, 2017). Zeytinyağı, LDL-kolesterolü düşürmekte ve HDL-kolesterolü yükseltmektedir (Visioli ve Galli, 1998: 4292; Carluccio, 2007: 1225).

Geleneksel Akdeniz tarzı diyeti ile beslenen ülkelerde önemli ölçüde daha düşük ölüm oranları görülmüştür (Jaen, 2005; Waterman ve Lockwood, 2007). Öyle ki, zeytinyağı tüketiminin yaygın olduğu Güney Avrupa ve Akdeniz ülkelerinde diğer batı ülkelerine kıyasla düşük kardiyovasküler nedenli ölüm oranı görülmektedir (Owen, 2000; Covas, 2007: 333; Cicerale, 2008: 219).

$\mathrm{Bu}$ çalışma, zeytinyağı-sağlık arasındaki ilişkinin incelenmesi ve zeytinyağının gastronomi açısından değerlendirilmesi amacıyla yürütülmüştür. Nitel araştırma yöntemlerinden derleme tekniği kullanılarak gerçekleştirilmiş bir çalışmadır (Berg ve Lune, 2019). Bu bağlamda, zeytin meyvesine ilişkin kavramsal çerçeve verilmiş; zeytinyağının kalitesine etki eden faktörlere ve zeytinyağının sağlık etkilerine vurgu yapılmış, Türk mutfak kültüründe zeytinyağı kullanımı değerlendirilmiştir.

\section{KAVRAMSAL ÇERÇEVE}

Zeytinin gerçek kökeni bilinmemektedir, ancak Suriye veya muhtemelen Sahra altı Afrika olduğu düşünülmektedir. 6000 yıldan fazla bir süredir, ekili zeytin Akdeniz medeniyetleri ile birlikte gelişmiştir (Harwood ve Yaqoob, 2002: 685). Avrupa, Orta Doğu ve Kuzey Afrika'daki birçok köy 
farklı çeşitlere sahiptir. Kaliforniya, Şili, Arjantin, Güney Afrika ve Avustralya'da da yeni zeytin çeşitleri dikilmiştir (Baldoni ve Belaj, 2009). "California Stili" siyah sofralık zeytin, Amerika Birleşik Devletleri dışında neredeyse bilinmemektedir ve bu çok hafif aromalı zeytin, büyük ölçüde pizzalarda kullanılmaktadır. Yağ stilleri çeşitlidir ve çoğu zeytin meyvesi yağa dönüştürülmektedir (Kiritsakis, Turkan ve Kiritsakis, 2005).

Zeytinyağı, geleneksel Akdeniz Diyetinin en temsili besinidir. Zeytinyağının sağlık faydalarından dolayı (Covas vd., 2006; Kiritsakis ve Shahidi, 2017) Avrupa Gıda Güvenliği Otoritesi (European Food Safety Authority ya da EFSA) günde $5 \mathrm{mg}$ hidroksitirozol tüketilmesini önermektedir. Bu miktarda hidroksitirozol alabilmek için günde en az 20 gram natürel sızma zeytinyağı tüketilmesi gerekmektedir (López-Miranda vd., 2010). Türkiye Esnaf, Sanatkarlar ve Kooperatifçilik Genel Müdürlüğü Zeytin ve Zeytinyağı Raporuna göre (2019), Türkiye'nin zeytinyağı tüketiminin istikrarlı olarak arttığı fakat kişi başına düşen yıllık zeytinyağı tüketiminin 2 litre olduğu bilinmektedir.

Zeytinyağı turizmi, Akdeniz ülkelerine gelir sağlamaktadır (Arıkan Saltık, 2017). Zeytinyağ1 turizmi, zeytinyağı ve turizmi birleştirip turistlere çeşitli aktiviteler sunarak yapılmaktadır. Turistlere zeytinyağı üretim sürecine katılma imkanı tanıma, yerinde gözlem ve konaklama sağlama, ziyaretçilere zeytinyağı satmak, zeytinyağı turizmi kapsamında yer alan faaliyetler arasındadır (Alonso ve Northcote, 2010).

Yunanistan, Portekiz, Fransa, Fas ve Tunus, İtalya gibi Akdeniz ülkelerinde, turistlere geleneksel zeytinyağı üretiminin gösterilmesi, zeytinyağının tematik müzelerde sergilenmesi, fuar ve festivallerde zeytin ve zeytinyağının tanıtımı, zeytin yetiştirme alanlarına seyahat yaygındır (Arıkan Saltık, 2017). Akdeniz Diyeti, 2010 yılında UNESCO tarafından insanlığın somut olmayan kültürel mirasına dahil edilmiştir (Avrupa Konseyi, 2011). Buna ek olarak, gastronomik kimliğin ve mirasın sembolü olarak zeytin, ayrıcalıklı bir destinasyon imajı yaratmada ve marka değeri oluşturmada önemli bir rol oynamaktadır (Fox, 2007).

\section{ZEYTINYAĞININ KALITESINNE ETKİ EDEN FAKTÖRLER}

Zeytinyağının kalitesi, zeytin çeşidi, zeytin ağacı yetiştiriciliği, zeytin toplama, depolama ve işleme işlemleri gibi farklı faktörlere bağlıdır (Covas vd., 2006). Zeytinin ezilmesi, sızma zeytinyağının organoleptik ve besleyici nitelikleri üzerinde önemli bir etkiye sahiptir. Sızma zeytinyağları, fenolik içerik bakımından rafine zeytinyağına göre daha zengindir (Kiritsakis ve Shahidi, 2017). Değirmen taşları kullanıldığında, elde edilen yağlar daha düşük acılık ve keskinliğe sahiptir çünkü bu kırma yöntemi daha düşük fenolik madde içeriğine sahip yağ üretmeye yardımcı olmaktadır. Metalik kırıcılar ile çıkarılan yağlar, şiddetli etki nedeniyle daha yüksek fenolik bileşik içeriğine sahiptir. Bu sebeple daha acı ve keskindir (Morales, Luna ve Aparicio, 2005).

Yağın, zeytin hamurunun katı ve sıvı fazlarından ayrılması basınç, süzme veya santrifüj sistemleri kullanılarak gerçekleştirilmektedir (Aguilera, 2005). Zeytin meyveleri sağlam ve doğru olgunluktaysa tüm sistemler kaliteli yağ sağlayabilmektedir (Kiritsakis ve Shahidi, 2017).

Endülüs'te iki farklı lokasyonda yetiştirilen, İtalyan zeytin çeşitleri olan Frantoio ve Leccino'dan elde edilmiş sızma zeytinyağlarının karakterizasyonu üzerine 1999/2000 ve 2001/2002 ekin yıllarında çalışmalar yapılmıştır. Farklı ortamlarda yetişen, aynı çeşit zeytinden çıkarılan yağlar arasında önemli farklılıklar olduğu sonucuna varılmıştır. Daha yüksek rakımda, yağlar daha fazla oleik asit içeriği ve daha yüksek stabilite gösterirken, alçak rakımlı bölgeden çıkarılan zeytinlerden elde edilen yağlar daha yüksek tokoferol ve linoleik asit içeriğine sahiptir (Aguilera, 2005; Morales, Luna ve Aparicio, 2005). 


\section{ZEYTINNYAĞINDA TAT OLUŞUMUNU SAĞLAYAN BİLEŞENLER}

Zeytinyağının eşsiz ve hassas tadı, içeriğindeki uçucu bileşenlerle ilişkilendirilebilir. Zeytinyağındaki aroma bileşenlerinin varlığı, duyusal kalitesiyle yakından ilgilidir (Kiritsakis ve Shahidi, 2017).

Zeytin meyvesinde enzimatik bir işlemle uçucu aroma bileşikleri oluşmaktadır (Morales, Luna, ve Aparicio, 2005). Zeytin çeşidi, meyvenin menşei, olgunluk aşaması, meyvenin saklama koşullarını; zeytinin işlenmesi zeytinyağının lezzet bileşenlerini ve dolayısıyla tadı ve aromasını etkilemektedir. Oktanal, nonala ve 2-heksenal bileşenleri ile uçucu alkoller propanol, amil alkoller, 2-heksenol, 2-heksanol ve heptanol, zeytin çeşidini karakterize eder (Aparicio ve Harwood, 2013; Kiritsakis ve Shahidi, 2017).

Zeytin meyvesinin depolanması sırasında aldehitler ve esterler gibi uçucu aroma bileşenleri azalmaktadır (Morales, Luna ve Aparicio, 2005). Meyvede oksidasyonun etkisi ile çeşitli tatsız bileşikler oluşabilmektedir. Pentanal, hexanal, octanal ve nonanal, oksitlenmiş zeytinyağında oluşan başlıca bileşiklerdir, ancak 2-pentenal ve 2-heptenal kötü lezzetten esas olarak sorumludur (Kiritsakis, 1998; Aparicio ve Harwood, 2013).

\section{ZEYTINNYAĞININ SAĞLIK ETKİLERİ}

Zeytinyağı, Akdeniz diyetindeki birincil yağ kaynağıdır. Akdeniz diyeti kavramı 1950'lerde araştırmacı Ancel Keys tarafından başlatılan "Yedi Ülke" araştırmasından sonra doğmuştur. Akdeniz diyetinin temel özellikleri arasında; baklagil ve tahıllarca zengin, ana kaynak olarak zeytinyağı kullanımı; balık ve kümes hayvanı tüketimi kırmızı etin nispeten düşük tüketimi ve öğünlerle birlikte şarap tüketimi yer almaktadır $(\mathrm{Hu}, 2003)$.

Zeytinyağında bulunan oleik asit, hidroksitirosol ve kafeik asit kansere karşı büyük koruma faktörleri göstermiştir. Skualenin de antikanser etkileri olduğu tespit edilmiştir. Zeytinyağ tüketiminin kolon için faydası vardır ayrıca göğüs kanserinin önlenmesinde etkendir (Waterman ve Lockwood, 2007; Kiritsakis ve Shahidi, 2017).

İspanya, Yunanistan ve İtalya gibi, sızma zeytinyağının ana yağ kaynağı olduğu ülkelerde, kanser insidansı oranları kuzey Avrupa ülkelerinden daha düşüktür. Sızma zeytinyağının koruyucu etkisinin sağlanabilmesi için ergenlik çağından önce tüketilmeye başlanması ve yaşam boyu sürdürülmesi gerekmektedir (Jaen, 2005; Waterman ve Lockwood, 2007).

Akdeniz diyeti (sızma zeytinyağı bakımından zengin) kardiyovasküler hastalık riskini azaltmaktadır (Armutcu vd., 2013). Akdeniz diyeti, lipoprotein profili, kan basıncl, glikoz metabolizması ve antitrombotik profil gibi kardiyovasküler hastalıklar için başlıca risk faktörlerini iyileştirmektedir (Kiritsakis ve Shahidi, 2017).

Zeytinyağı, tekli doymamıs yağ asitleri bakımından zengin olmasının yanı sıra, antioksidan özelliklere sahip küçük bileşenler içermektedir (Fitó, de la Torre ve Covas, 2007). Bunun sebebi, Akdeniz havzasındaki zeytin ağaçlarının, kendilerini çevresel stresten korumak için bir dizi antioksidan savunma geliştirmeleridir (Visioli, Bellomo ve Galli, 1998; Aparicio ve Harwood, 2013). Oksidatif stres, vücudun oksidan ve antioksidan sistemleri arasında oksidanlar lehine bir dengesizlik olarak tanımlanmaktadır. Serbest radikallerin ürettiği oksidatif stres, kanser ve nörodejeneratif hastalıklar gibi çeşitli hastalıkların gelişimi ile ilişkilendirilmiştir (Fitó, de la Torre ve Covas, 2007). Protokatekuik ve siringik asidin de antioksidan aktiviteye sahip olduğu bulunmuştur. Tirosol, p-hidroksifenilasetik asit, o-kumarik asit, p-kumarik asit, phidroksibenzoik asit ve vanillik asit çok az etkiye sahip olduğu görülmüş veya hiç etki 
göstermediği saptanmıştır. Yağın stabilitesine katkıları çok az düzeydedir (Papadopoulos ve Boskou, 1991; Aparicio ve Harwood, 2013).

\section{Akdeniz Beslenme Piramidi}

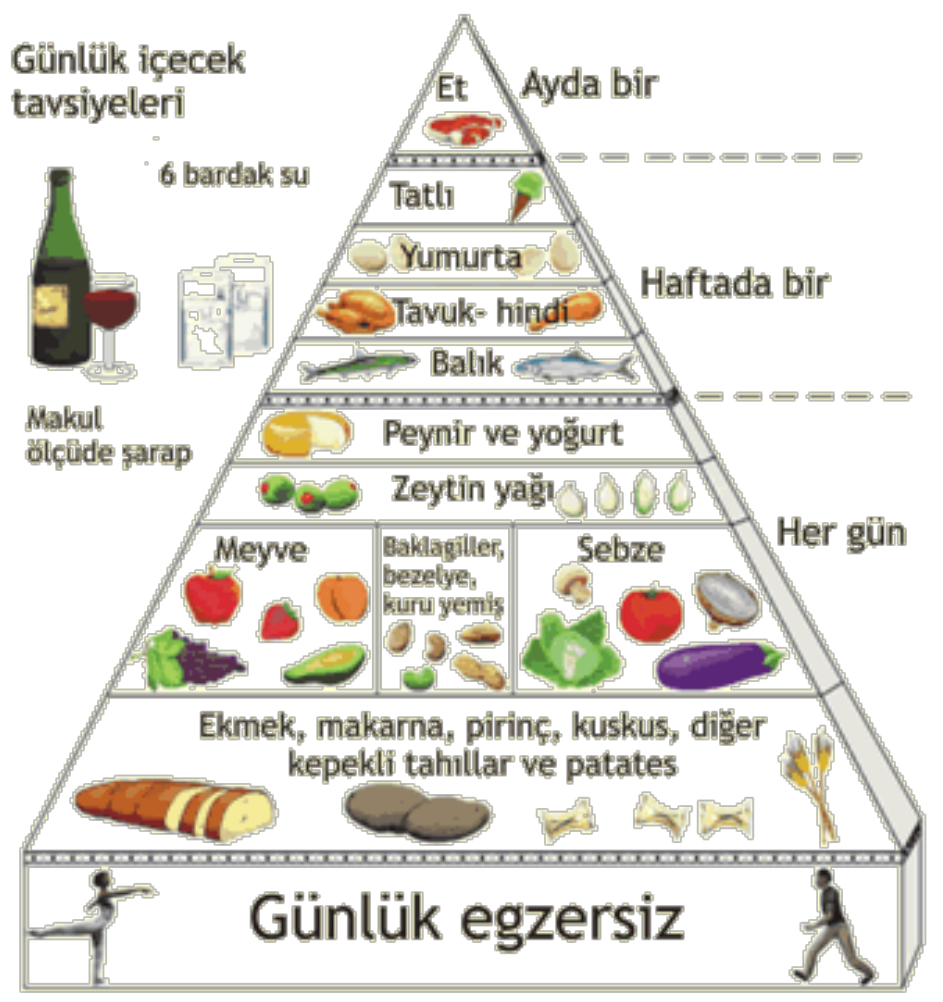

Resim 1: Akdeniz Beslenme Piramidi

Kaynak (Özdoğan, 2021).

Ferrara, (2000) çalışmasında, tekli doymamış (MUFA) (sızma zeytinyağı) ve çoklu doymamış yağ asitlerinin (PUFA) (ayçiçek yağı) antihipertansif etkileri arasındaki olası farkları değerlendirmiştir. MUFA diyetini alanların \%8'inin ilaç tedavisine ihtiyacı olmadığı anlaşılmıştır. Sonuç olarak, natürel sızma zeytinyağı kullanımıyla birlikte doymuş yağ alımında hafif bir azalma, günlük antihipertansif ilaç dozu gereksinimi önemli ölçüde azaltmaktadır.

Yeni preslenmiş sızma zeytinyağı, keskinliği boğazda güçlü bir batma hissi uyandıran bir bileşik olan oleocanthal içermektedir. Bu madde anti-inflamatuar ilaç olan ibuprofen1'in solüsyonlarındandır. Burada, oleokantın ibuprofeninkine çarpıcı bir şekilde benzer bir profile sahip doğal bir anti-enflamatuar bileşik olarak hareket etmesi, farmakolojik aktivitenin bir göstergesidir (Beauchamp, 2005). Bu bağlamda, iltihap önleyici ve inhibe edici olarak kabul edilmektedir (Kiritsakis ve Shahidi, 2017).

Yaşlanma, bununla ilgili olan ateroskleroz, morbus Parkinson, Alzheimer hastalığı, bilişsel gerileme gelişmiş ülkelerde büyük bir endişe kaynağıdır. Tekli doymamış yağ asitleri (MUFA) 
yaşa bağlı bilişsel gerileme ve Alzheimer hastalığına karşı koruyucu olarak kabul edilmektedir (Kiritsakis ve Dugan, 1985; Berr vd., 2009; Aparicio ve Harwood, 2013).

Zeytinin "karasuyu" da güçlü antioksidan ve radikal temizleyiciler olan bileşiklere sahiptir. Hidroksitirosol ve oleuropeinin, klinik bakteri suşlarına karşı antimikrobiyal aktiviteye sahip olduğu gözlenmiştir (Tuck ve Hayball, 2002).

\section{TÜRK MUTFAK KÜLTÜRÜNDE ZEYTINNYAĞI KULLANIMI}

Zeytinyağı kendine has aroması ile Türk mutfak kültüründe büyük bir yere sahiptir. Zeytinyağ mutfaklarda tatlıdan, tuzluya her yemeğe uyum sağlayabilen bir gıdadır (Şavkay, 2000). Ancak her zeytinyağı aynı fonksiyona ve besleyici içeriğe sahip değildir. Zeytinin çeşidi ve hasat zamanı, bakım koşulları yağın kalitesini etkilemektedir (Kiritsakis ve Shahidi, 2017). Buna binaen bazı yağlar sağlık faydası için bazı yağlar ısıl işlem uygulanarak yemeklerde kullanılabilmektedir (Muğla İl Kültür ve Turizm Müdürlüğü, 2021). Zeytinyağlı sebze yemeklerini oda isısında tüketmek gerekmektedir. Böylelikle kendisine has olan tat daha kolay algılanmaktadır. Zeytinyağı çorbalar, sebze yemekleri, balıklar, pizzalar ve salatalarda yaygın olarak kullanılmaktadır (Hürriyet Gazetesi, 2018). Genellikle ot salatalarında sos olarak limon, tuz, zeytinyağı üçlüsü kullanılır (Şavkay, 2000).

Fesleğen, domates sosu ve sarımsak zeytinyağına en çok yakışan yiyeceklerdendir. Zeytinyağının kahvaltıda, fırın yemeklerinde, kızartmalarda, sotelerde, ızgaralarda kullanımı görülmektedir (Muğla İl Kültür ve Turizm Müdürlüğü, 2021). Zeytinyağı asit içeriği ile yiyecekleri (kırmızı et, balık, tavuk, hindi ürünleri) terbiye etmede kullanılmaktadır (Ardakoç, 2001; Türkan, 2004). Makarna, pizza, et, balık veya sebze yemekleri ile tüketilen sosların içeriğinde görülmektedir. Zeytinyağı yemeklerde kullanılan her tür baharatın özelliğini daha çok açığa çıkaran bir çözünürlük etkisi oluşturmaktadır. Ürünlere farklı aromalar katarken aynı zamanda parlak olmalarını da sağlamaktadır (Hürriyet Gazetesi, 2018).

Zeytinyağı, kurabiye ve kek yapımında kullanıldığında ürünlere yapı kazandırmaktadır. Yiyeceklerin ömrünü arttıran bir fonksiyona da sahiptir. Dondurma işlemi olmadan, et ürünlerine zeytinyağı uygulandığında ömürlerini birkaç gün uzatmaktadır (Hürriyet Gazetesi, 2018).

Meze tabaklarında zeytinyağlılar büyük yer kaplamaktadır (Şavkay, 2000). Zeytinyağlı Yerelması, Zeytinyağlı Hamsili Pazı Yaprağı Dolması, Zeytinyağlı Semizotu, Zeytinyağlı Ispanak, Zeytinyağlı Patlıcan Paçası, Kabak Tava, Zeytinyağlı Gelincik, Zeytinyağlı Mevsim Türlüsü,Zeytinyağlı Patlıcan ve Lahana Dolması, Zeytinyağlı Kuru Fasulye, Zeytinyağlı Kuru Bakla, Zeytinyağlı Enginar, Zeytinyağlı Pırasa, Zeytinyağlı Barbunya, Zeytinyağlı Bakla, Zeytinyağlı Ekşi Kabak, Zeytinyağlı Kereviz, Kabak Mücver(zeytinyağlı), Zeytinyağlı Yeşil Mercimek Çorbası, Patlıcan Pilaki, Havuç Tava zeytinyağlı yemekler arasında gösterilebilmektedir (Ardakoç, 2001; Türkan, 2004).

\section{SONUÇ}

Zeytinyağı, zeytin meyvesinden elde edilen bir yağdır. Zeytinyağındaki fenoller, zeytinyağına kendine özgü keskin tadı vermektedir ve yüksek stabilitesinden sorumludur. Zeytinyağı, yüksek seviyelerde tekli doymamış yağ asitleri içeriği ile bilinmektedir ve aynı zamanda polifenolik bileşikler, skualen ve a-tokoferol ile iyi bir fitokimyasal kaynağıdır. 
Zeytinyağı, Akdeniz diyetinin ayrılmaz bir bileşenidir. Zeytinyağ yoğunluklu lipoproteinlerin oksidasyonunu engellemektedir. Yüksek kaliteli zeytinyağı içeren diyetler sağlıklı olarak ifade edilebilecek güçlü biyolojik aktivitelere sahiptir. Zeytinyağının düzenli tüketiminin, koroner kalp hastalığı risk faktörlerini azaltan, çeşitli kanser türlerinin önlenmesini sağlayan, bağışıklığın güçlenmesinde yardımcı ve antienflamatuar olma gibi sağlık yararları vardır.

Türk mutfak kültüründe zeytinyağı önemli bir yere sahiptir. Zeytinyağının kızartmalarda, sotelerde, kahvaltıda, fırın yemeklerinde, ızgaralarda kullanımı görülmektedir. Zeytinyağı çorbalar, sebze yemekleri, balıklar, pizzalar ve salatalarda yaygın olarak kullanılmaktadır.

Zeytinyağının sağlık faydaları ülkelerin turizm gelirlerine katkı sağlamaktadır. Yerli ve yabancı turistlere zeytinyağı üretim sürecine katılım sağlama, yerinde gözlem ve konaklama imkanı verme, zeytinyağı ürünleri satma zeytinyağı turizmi kapsamında yer alan faaliyetler arasındadır. Gastronomik kimliğin ve mirasın sembolü olarak zeytinyağı, ayrıcalıklı bir destinasyon imajı yaratmada ve marka değeri oluşturmada önemli bir rol oynamaktadır.

Bu çalışmada, zeytinyağı ve sağlık ilişkisine vurgu yapılmış, zeytinyağının, kişilerin genel sağlık durumuna katkıda bulunabilecek fonksiyonel bir gıda örneği olduğuna dikkat çekilmiş, Türk mutfak kültüründe zeytinyağı kullanımı değerlendirilmiştir. Çalışmanın benzerlerinin diğer fonksiyonel gıdalar için yapılması halk sağlı̆̆ının gelişimi ve toplumsal bilinci arttırmada önem arz etmektedir.

\section{KAYNAKLAR}

Aguilera, M. P., Beltrán, G., Ortega, D., Fernández, A., Jiménez, A., and Uceda, M. (2005). Characterisation of virgin olive oil of Italian olive cultivars: Frantoio' and Leccino', grown in Andalusia. Food Chemistry, 89(3), 387-391.

Aguilera, A. D. and Northcote, J. (2010), The Development of Olive Tourism in Western Australia, International Journal of Tourism Research, 12, 696-708

Aparicio, R., and Harwood, J. (2013). Handbook of olive oil (pp. 431-478). Boston, MA, USA:Springer.

Ardakoç, B. (2001). Türk Sofrası, İstanbul: Geçit Kitabevi.

Armutcu, F., Namuslu, M., Yüksel, R., ve Kaya, M. (2013). Zeytinyağı ve sağlık: Biyoaktif bileşenleri, antioksidan özellikleri ve klinik etkileri. Konuralp Tıp Dergisi, 5(1), 60-68.

Avrupa Konseyi (2010). The Routes of The Olive Tree at International Forum on Mediterranean Diet, http://culture-routes.net/news/routes-olive-tree-international-forum-mediterraneandiet (Erişim Tarihi: 02.02.2021).

Beauchamp, G. K., Keast, R. S., Morel, D., Lin, J., Pika, J., Han, Q., and Breslin, P. A. (2005). Ibuprofen-like activity in extra-virgin olive oil. Nature, 437(7055), 45-46.

Berg, B. L. ve Lune, H. (2019). Sosyal Bilimlerde Nitel Araştırma Yöntemleri. Konya: Eğitim Yayınevi.

Berr, C., Portet, F., Carriere, I., Akbaraly, T. N., Feart, C., Gourlet, V., and Ritchie, K. (2009). Olive oil and cognition: results from the three-city study. Dementia and Geriatric Cognitive Disorders, 28(4), 357-364.

Baldoni L., and Belaj A. (2009) Olive. In: Vollmann J., Rajcan I. (eds) Oil Crops. Handbook of Plant Breeding, vol 4. Springer, New York, NY. https://doi.org/10.1007/978-0-387-77594-4_13. 
Carluccio, M. A., Massaro, M., Scoditti, E., and De Caterina, R. (2007). Vasculoprotective potential of olive oil components. Molecular Nutrition \& Food Research, 51(10), 1225-1234.

Cicerale, S., Conlan, X. A., Sinclair, A. J., and Keast, R. S. (2008). Chemistry and health of olive oil phenolics. Critical Reviews in Food Science and Nutrition, 49(3), 218-236.

Covas, M. I., Nyyssönen, K., Poulsen, H. E., Kaikkonen, J., Zunft, H. J. F., Kiesewetter, H. and Marrugat, J. (2006). The effect of polyphenols in olive oil on heart disease risk factors: a randomized trial. Annals of Internal Medicine, 145(5), 333-341.

Covas, M. I. (2007). Olive oil and the cardiovascular system. Pharmacological Research, 55(3), 175186.

Di Giovacchino, L., Sestili, S., and Di Vincenzo, D. (2002). Influence of olive processing on virgin olive oil quality. European Journal of Lipid Science and Technology, 104(9-10), 587-601.

Ferrara, L. A., Raimondi, A. S., d'Episcopo, L., Guida, L., Russo, A. D., and Marotta, T. (2000). Olive oil and reduced need for antihypertensive medications. Archives of Internal Medicine, 160(6), 837-842.

Fitó, M., de la Torre, R., and Covas, M. I. (2007). Olive oil and oxidative stress. Molecular Nutrition $\mathcal{E}$ Food Research, 51(10), 1215-1224.

Fox, R. (2007), Reinventing the gastronomic identity of Croatian tourist destinations, Hospitality Management, 26, 546-59.

Gerber M. (1997). Olive oil, monounsaturated fatty acids and cancer. Cancer Letters 114: 91-92.

Harwood, J.L. and Yaqoob, P. (2002), Nutritional and health aspects of olive oil. Eur. J. Lipid Sci. Technol., 104: 685-697. https://doi.org/10.1002/1438-9312(200210)104:9/10<685:AIDEJLT685>3.0.CO;2-Q

Hu, F. B. (2003). The Mediterranean diet and mortality-olive oil and beyond. New England Journal of Medicine, 348(26), 2595-2596.

Hürriyet Gazetesi (2018). Zeytinyağı mutfakta nasıl kullanılmalı? https://www.hurriyet.com.tr/lezizz/zeytinyagi-mutfakta-nasil-kullanilmali-iste-cevabi-36921611 (Erişim Tarihi: 11.04.2021)

Arıkan Saltık, I. (2017). Türkiye'de Zeytinyağı Turizminin Başlangıç Uygulamaları.The Journal of Academic Social Sciences, 55-134-151.

Jaen. (2005). International conference on the healthy effect of virgin olive oil. European Journal of Clinical Investigation, 35(7), 421-424.

Kiritsakis, A., and Dugan, L. R. (1985). Studies in photooxidation of olive oil. Journal of the American Oil Chemists' Society, 62(5), 892-896.

Kiritsakis, A., and Markakis, P. (1988). Olive oil: a review. In Advances in food Research Academic Press, 31, 453-482.

Kiritsakis, A. K. (1998). Flavor components of olive oil-A review. Journal of the American Oil Chemists' Society, 75(6), 673-681.

Kiritsakis, A., Turkan, K. M., and Kiritsakis, K. (2005). Olive oil. Bailey's Industrial Oil and Fat Products, 1-38.

Kiritsakis, A., and Shahidi, F. (Eds.). (2017). Olives and Olive Oil as Functional Foods: Bioactivity, Chemistry and Processing. John Wiley \& Sons. 
Lipworth, L., Martínez, M. E., Angell, J., Hsieh, C. C., and Trichopoulos, D. (1997). Olive oil and human cancer: an assessment of the evidence. Preventive medicine, 26(2), 181-190.

López-Miranda, J., Pérez-Jiménez, F., Ros, E., De Caterina, R., Badimón, L., Covas, M. I., and Yiannakouris, N. (2010). Olive oil and health: summary of the II international conference on olive oil and health consensus report, Jaén and Córdoba (Spain) 2008. Nutrition, metabolism and cardiovascular diseases, 20(4), 284-294.

Loumou, A., C. Giourga, P. Dimitrakopoulos, and S. Koukoulas (2000). Tourism contribution to agro-ecosystems conservation: The case of Lesvos island, Greece. Environmental Management 26(4): 363-370.

Morales, M. T., Luna, G., and Aparicio, R. (2005). Comparative study of virgin olive oil sensory defects. Food Chemistry, 91(2), 293-301.

Muğla İl Kültür ve Turizm Müdürlüğü, (2021). https://mugla.ktb.gov.tr/TR-73679/zeytinyagikulturu.html (Erişim Tarihi: 15.03.2021).

Owen, R. W., Giacosa, A., Hull, W. E., Haubner, R., Spiegelhalder, B., and Bartsch, H. (2000). The antioxidant/anticancer potential of phenolic compounds isolated from olive oil. European Journal of Cancer, 36(10), 1235-1247.

Özdoğan, M. (2021). https://www.drozdogan.com/kategori/akdeniz-diyeti/ (Erişim Tarihi: 10.03.2021).

Papadopoulos, G., and Boskou, D. (1991). Antioxidant effect of natural phenols on olive oil. Journal of the American Oil Chemists' Society, 68(9), 669-671.

Stark, A. H., and Madar, Z. (2002). Olive oil as a functional food: epidemiology and nutritional approaches. Nutrition reviews, 60(6), 170-176.

Şavkay, T. (2000). Osmanlı Mutfağı, İstanbul: Şekerbank A.Ş. Basım Yayın.

Ticaret Bakanlığı- Türkiye Esnaf, Sanatkarlar ve Kooperatifçilik Genel Müdürlüğü (2019). 2018 yılı Zeytin ve Zeytinyağ1 Raporu, https://ticaret.gov.tr/data/5d41e59913b87639ac9e02e8/3acedb62acea083bd15a9f1dfa551bcc.pdf

Tuck, K. L., and Hayball, P. J. (2002). Major phenolic compounds in olive oil: metabolism and health effects. The Journal of Nutritional Biochemistry, 13(11), 636-644.

Türkan, C. (2004), Aşçılık Uygulamaları Yemek Hazırlama Tekniği, İstanbul: Değişim Yayınları.

Visioli, F., and Galli, C. (1998). Olive oil phenols and their potential effects on human health. Journal of Agricultural and Food Chemistry, 46(10), 4292-4296.

Visioli, F., Bellomo, G., and Galli, C. (1998). Free radical-scavenging properties of olive oil polyphenols. Biochemical and Biophysical Research Communications, 247(1), 60-64.

Visioli, F., and Galli, C. (2002). Biological properties of olive oil phytochemicals. Critical Reviews in Food Science and Nutrition, 42(3), 209-221.

Waterman, E., and Lockwood, B. (2007). Active components and clinical applications of olive oil. Alternative medicine review, 12(4). 